\title{
Challenges to Implementing Distributed Generation in Area Electric Power System
}

\author{
L.L. Lai \\ State Grid Energy Research Institute \\ Beijing, China \\ lailaili@sgeri.sgcc.com.cn
}

\author{
S.W. Chan and P.K. Lee \\ Powerpeg NSI Limited \\ Hong Kong, China \\ mc@powerpeg.com.hk
}

\author{
C.S. Lai \\ School of Engineering and Design \\ Brunel University \\ London, UK \\ me10ccl@brunel.ac.uk
}

\begin{abstract}
Nowadays, electricity is mainly produced by large central generation plants. However, generators with lower capacities are increasingly used for distributed generation (DG). Distributed generators are applicable for improving supply reliability with considerations of renewable energy, environmental protection, peak load shaving and deferred investments in network expansion. Comparing to central generation, DG technologies are flexible in size, fuel, operation and expandability. Most of DGs are installed at distribution level. Various kinds of loads as well as active compensation devices may be connected in parallel with DG. Moreover, low capacity generation systems are more susceptible to power quality issues. This paper presents challenges of implementation of DG in practical area electric power systems under the impacts from both utility side and demand side.
\end{abstract}

Index Terms-- Distributed Generation, Power Generation Control, Voltage Control, Power Quality, Harmonics, and Smart Grid

\section{INTRODUCTION}

Distributed generation (DG) is related to the use of small generating units installed at strategic points of the electric power system or locations close to load centers. DG can be used in an isolated mode or grid-connected ways, that is, supplying the consumer's local demand, or integrated into the grid supplying energy to the electrical power system. Distributed generation can run on renewable energy resources, fossil fuels or waste heat. Equipment ranges in size from less than a kilowatt $(\mathrm{kW})$ to tens of megawatts (MW). Distributed generation can meet all or part of a customer's power needs. Islanding local detection schemes are based on inverters, which cannot work under different operating conditions; therefore, they adopt different inverters according to the DGs. If connected to a distribution or transmission system, power can be sold to the utility or a third party [1-17].

DG and Renewable Energy Sources (RES) have attracted a lot of attention worldwide. Both are considered to be important in improving the security of energy supplies by decreasing the dependency on imported fossil fuels and in reducing the emissions of greenhouse gases (GHGs). The viability of DG and RES depends largely on regulations and stimulation measures that are a matter of political decisions.

Distributed generation technologies include engines, small wind turbines, small hydro, fuel cells and photovoltaic systems. Despite their small size, DG technologies are making stronger impacts in electricity markets. In some markets, DG is actually replacing the more costly grid electricity. However, there are technical issues that deserve attention. No single DG technology can accurately represent the full range of capabilities and applications or the scope of benefits and costs associated with DG. Some of these technologies have been used for many years, especially reciprocating engines and gas turbines. Others, such as fuel cells and micro turbines, are relatively new developments. Several DG technologies are now commercially available, and some will be introduced or substantially improved within the next few years. There are many issues in DG, such as power quality, integration, protection and control etc.

As mentioned, DG technologies include photovoltaic systems, wind turbines, bio-fuel generators, combine heat and power generation (CHP) and micro-turbines. Development of DG is not targeted for replacing existing power plants. Instead, DG is a supplement of central generation. For example, DG can be used to generate electricity during peak hours in order to reduce maximum $\mathrm{kVA}$ demand and is then turned off during off-peak period. DG is also applicable to defer upgrade of congested transmission or distribution networks or to defer development of a new costly central generation plant. The unit capital cost per kilowatt of a DG is usually higher than that of a large generation plant. However, DG by means of onsite production reduces transmission and distribution costs. The waste heat from onsite generation is reusable by customers. The fuel economy of certain CHP is better than that of conventional generation system. Moreover, DG is applicable for utilization of inexpensive fuels like landfill gas and biofuel [1].

One of the major factors affecting the speed of DG expansion is the global economy. Although, the international trend towards privatization of the electricity supply industry has resulted in a fast, uninhibited expansion of privately owned DG in both distribution and transmission networks, this 
is not happening without issues. There is a natural conflict between the requirements of the power utility, whose primary concern is the network security, and the requirements of the DG whose primary objective is profit via the commercial production of electrical energy. Additionally, under deregulation, new plants are being built on more short-term, cost-based decisions. Long-term investments such as largescale expensive power plants or advanced communication based protection and automation infrastructures are not favored in deregulated markets where customers cannot be secured. As it is often difficult to resolve such conflicting interests, apart from the utilities and DG owners, the restructured electricity market is not projected to stimulate renewable energy technologies unless required by government policies as it is foreseen that renewable resources will remain more costly than fossil fuel alternatives to at least 2015 [2].

With the connection of DG, power systems become more complicated. The main difficulties that researchers encounter are not the lacking data but the efficiency of using the complex electrical quantities. Penetration of DG leads to changes to regulations and market rules. In contrast with generations of utilities, distributed generators are usually adjacent to consumers' sites or at local distribution plants. They are connected to point of common coupling (PCC) in parallel with loads in an area electric power system (Area EPS) [14]. Naturally, power quality events and natures of loads affect operation of DG. In fact, distributed generators receive impacts from both supply side and demand side.

\section{DG AT AREA EPS}

Nowadays, area EPS is complex. Fig. 1 shows a typical connection of DG in parallel with various kinds of loads and compensation devices.

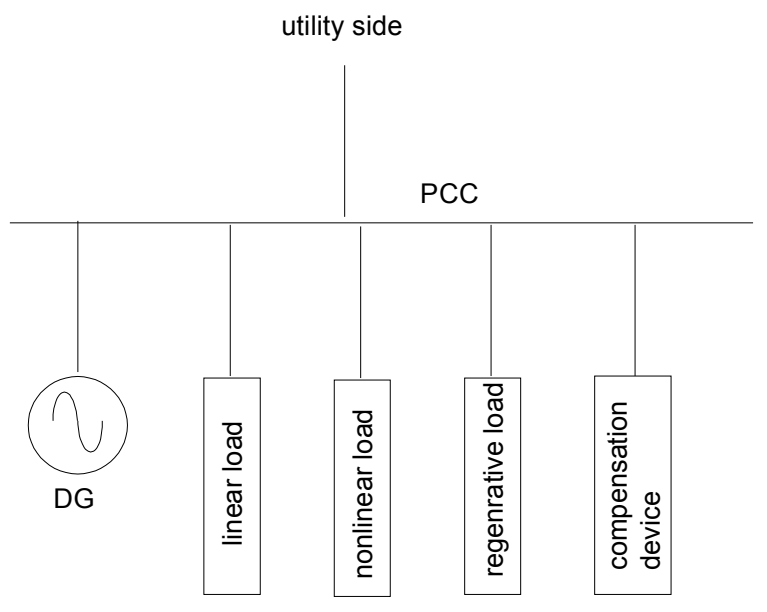

Figure 1: DG connected to area EPS
Linear loads include heaters and incandescent lamps. Nonlinear loads are mainly power electronic devices like computers, variable speed drives (VSD) and office automation equipment. Regenerative loads are usually cranes and hoisting machines. Due to the presence of nonlinear loads, compensation devices like active harmonic filters are adopted by customers. Regenerative current, surge current and harmonics affect operation of the DG. On the other hand, power quality issues propagate across transmission and distribution networks and impose impacts on the DG. Thus, there are challenges to ensure stable operation of distributed generators because they will receive disturbances from all directions.

\section{SYSTEM DISTURBANCES}

Voltage dip is one of the common disturbances travelling across transmission and distribution networks that affect operation of a DG. The voltage and current waveforms of a $330 \mathrm{~kW}$ DG during voltage dip is shown in Fig. 2. The remaining voltage of the voltage dip was around $60 \%$ that lasted for about $250 \mathrm{~ms}$. Under normal operation, the power generated by the DG plus the power from utility was equal to total consumption of the loads. No energy flowed from the DG to the utility side. When a fault occurred at the supply side and led to the voltage disturbance, a large amount of energy was delivered toward the fault point to cause reverse power flow.

As a result, output current of the DG increased rapidly to such a level that tripped itself. Even worse, the earth leakage protection device at the supply side malfunctioned to isolate the ac source because of the distorted surge current during reverse power flow. The area EPS suffered from power interruption after the short duration voltage dip. The loading current dropped to zero even though the voltage at utility side was restored shortly.
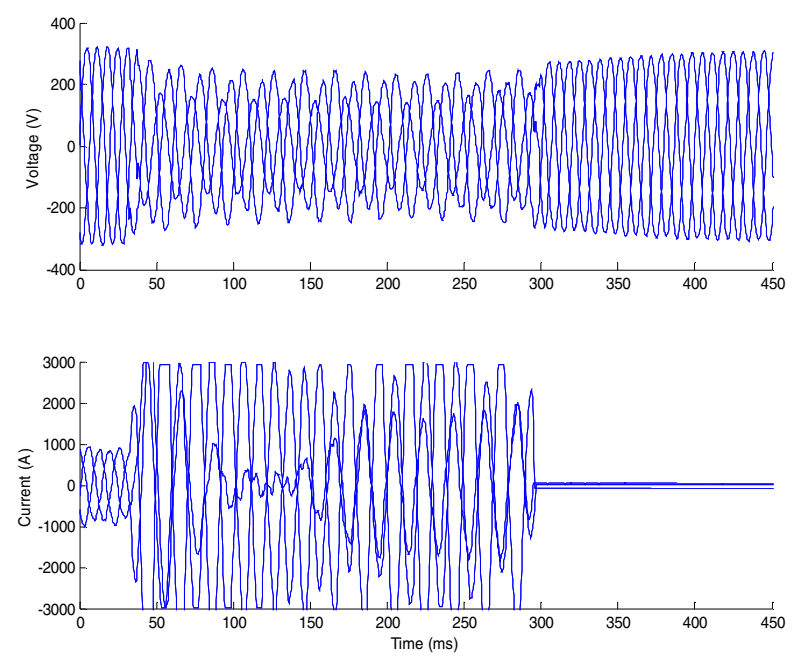

Figure 2: Voltage and current of DG during voltage dip 
In order to mitigate the impacts of voltage disturbance on DG, coordination of overcurrent and earth fault protection should be intensively designed with the consideration of bidirectional power flow. Fault current limiter is applicable for solving the directional overcurrent protection coordination problem [15]. Additional protection schemes like loss of main protection, under voltage protection, and reverse power protection are applicable to prevent reverse power flow and hence eliminate the possibility of mal-operation of protection devices.

\section{REGENERATIVE LOAD}

The protections of radial distribution networks are usually designed with the assumption that the power flows are unidirectional from the utility side at high voltage level downstream to the loads at low voltage level. Violation of this assumption could defeat the protection coordination and may be prohibited by utilities for the sake of safe operation and other tariff issues. On-grid connection of distributed generators may change the power flow if the generation exceeds the consumption. Sudden load change because of equipment failure at demand side could be a problem. Regenerative loads are another cause of reverse energy flow.

The load profile of a crane is shown in Fig. 3. The crane consisted of a VSD that allowed bidirectional flow of energy. Positive power was recorded when cargo was lifted up whereas negative power was observed when the cargo was delivered to a container cargo ship. Fig. 4 shows the current and power factor profiles. If there is no other passive load, the regenerated power will flow back to the distributed generator or to the utility side.

Reverse power could be problematic because directional protection schemes might be adopted at transmission level. Moreover, reverse voltage gradient could be developed along a radial circuit and the voltage tolerance will be affected.

When reverse power occurred, the power factor changed from positive value to negative value. The implication is that the phase angle between voltage and current shifts beyond $90^{\circ}$. It may affect the stability of distributed generator operated in power factor control (PFC) mode [16]. Therefore, the settings of directional protection devices should be intensively revised to cope with the characteristics of regenerative loads.

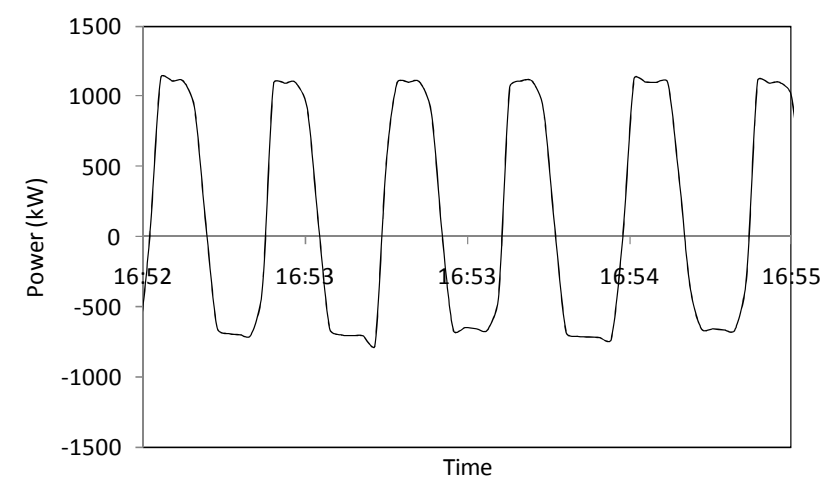

Figure 3: Load profile of crane

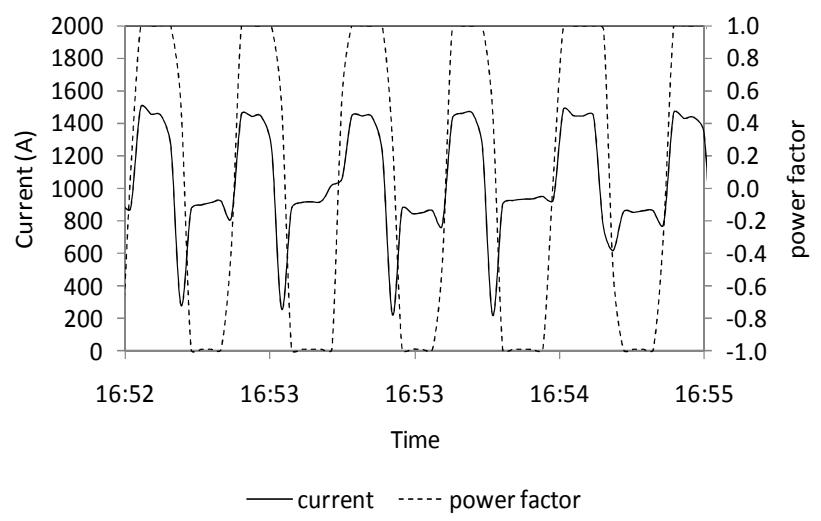

Figure 4: Load profile of crane

\section{ACTIVE COMPENSATION DEVICE}

A modern area EPS not only consists of passive linear loads, but also various power electronic devices, active compensation devices like active harmonic filter, voltage dipproofing inverter, active voltage restorer and so on.

Fig. 5 shows the output current profile of a $550 \mathrm{~kW}$ DG connected to an area EPS with the presence of a 400A active harmonic filter. The system was designed for on-grid and intentional islanding connections. During routine maintenance of the supply panel, the area EPS was disconnected from the utility supply. A number of nonessential loads were switched off and the DG was restarted to support the operation of the essential load. Actually, the essential load was a VSD with active harmonic filter connected in parallel.

The system was unstable and current fluctuated dramatically until the DG tripped. However, the system became stable with the active harmonic filter defeated. Analysis revealed that the low capacity DG was a weak source. Frequency variation of the DG due to load changes is larger than that of central generation. Deviation of frequency was observed whenever power consumption changed. Moreover, the response time of the active harmonic filter was faster than that of the DG. The filter misinterpreted the frequency deviation as harmonics and injected compensation current to the system. Meanwhile, the DG generated larger current due to increase of the compensation current. Finally, the system oscillated until internal overload protection of the generator was triggered to cease generation.

Fig. 6 shows the voltage and current waveform under normal operation of the DG. Sinusoidal waves were observed as harmonics generated from the VSD were compensated by using the active harmonic filter. Distorted waveforms as shown in Fig. 7 were recorded when the system was entering unstable state. Compensation current generated by the active harmonic filter led to the distortion instead of restoring the loading current into sinusoidal wave.

Smart meters were installed to tackle the problem. The power conditions at PCC and output of the generator were monitored continuously. When the supply source was disconnected, the smart meter defeated the active harmonic 
filter until the distributed generator ran into steady state. The active harmonic filter was readjusted with a slower response time. As nonessential loads were switched off, the function of reactive power compensation of the filter was also deactivated. In brief, the settings of active compensation device should be revised to cope with the operation of DG in islanding mode in order to avoid unstable operation [17].

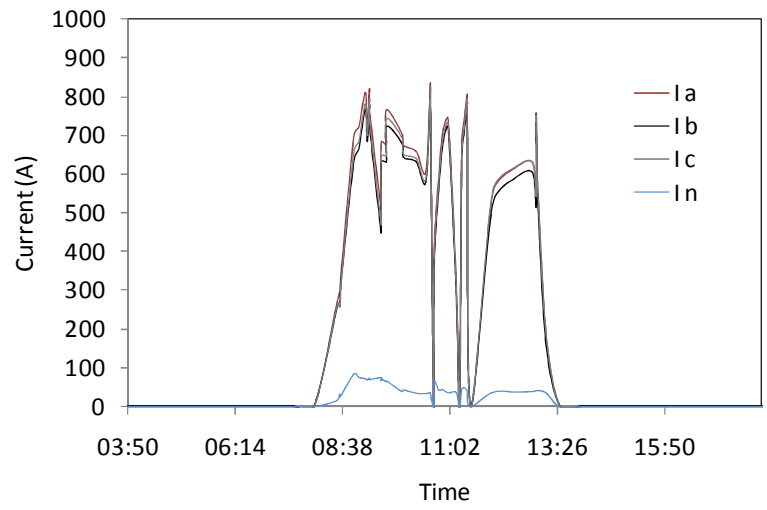

Figure 5: Current profile of DG with presence of active harmonic filter

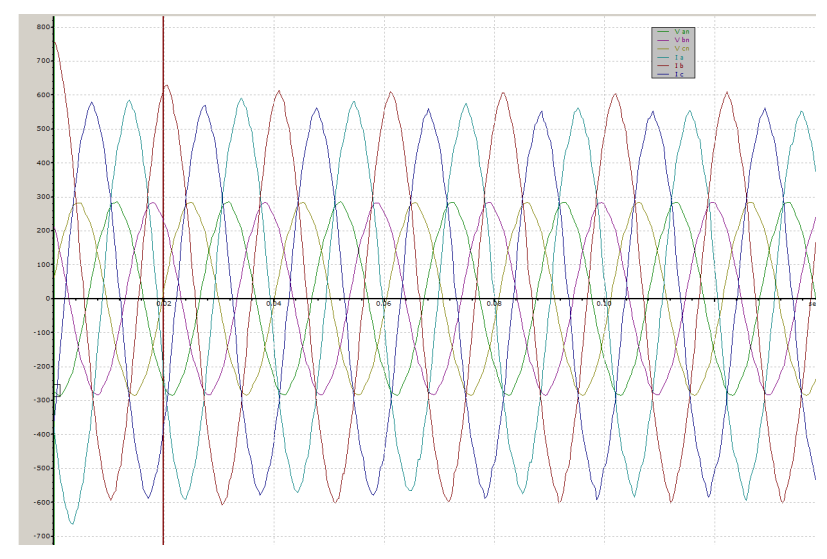

Figure 6: Voltage and current waveforms of generator at normal state

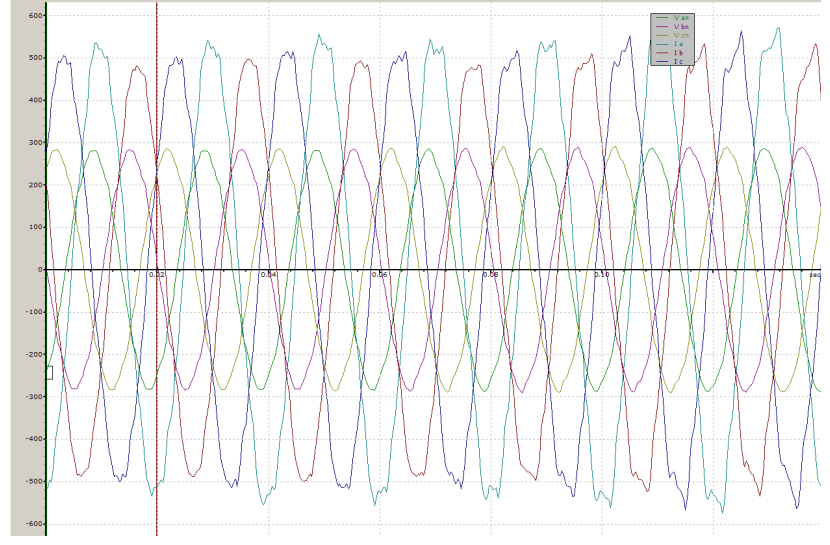

Figure 7: Voltage and current waveforms of generator at unstable state

\section{PARALlELIZATION OF Distributed GENERATORS}

Two or more generators are required for a DG in islanding mode to supply bulk consumers. However, the generators are probably of different ratings and characteristics. Coordination among the generators is a challenge of parallelization. Fig. 8 shows the load profile and frequency variation measured at an area EPS with two different types of distributed generators. The power ratings of the generators were almost the same, but the models and control circuits were different.

It was a pitfall that the response time of one of the generators was slower than that of the other one. The generators operated independently and their respective control circuits were not connected with any communication for coordination. It is difficult for the generators to dynamically share loads according to their capacities, characteristics and load changes. As a usual practice, the generator with slower time response was preset to bear the base load, whereas the generator with faster response time was dedicated for load changes. A large portion of the total power consumption was supplied by the generator of slower response. Power consumption dropped rapidly when a heavy load was switched off. Surplus power generated by the generator with slower response time caused the increase of supply frequency. Obviously, the response time of the generator generated the larger output power dominated the system response.

As short term mitigation, the preset output power of the slower generator was reduced so that the faster generator would bear a larger portion of total power consumption. As a long term solution, smart meters are applicable to achieve dynamic load sharing and coordination among the distributed generators. 


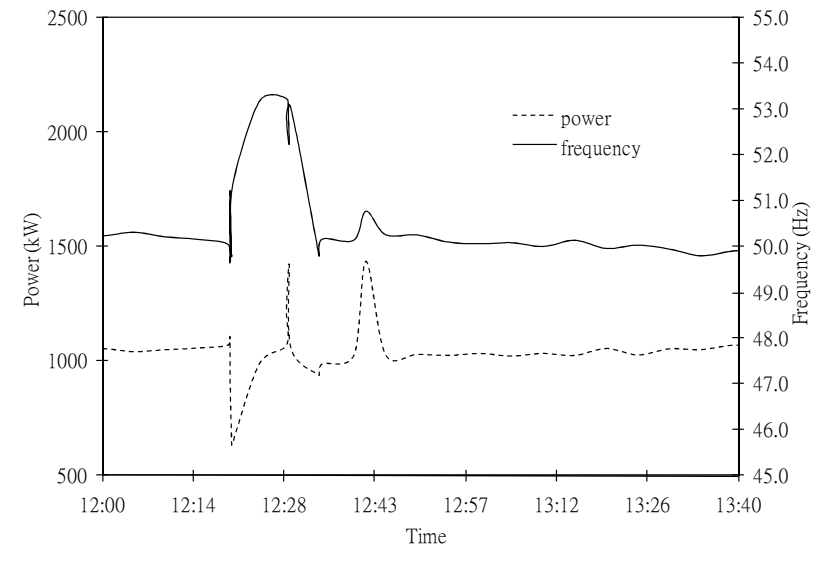

Figure 8: DG frequency affected by deceleration of motor

\section{CONCLUSIONS}

DG is being used increasingly around the world with the considerations of renewable energy, environmental protection, supply reliability, and high initial cost of new central generation plant. Impacts from supply side and demand side on DG are non-negligible. Challenges of implementation of DG on area electric power system are described based on practical cases. Mitigations by means of coordination, intensive design of protection and smart metering are introduced.

Integration of large-scale renewable energy sources and small size generating facilities into the electricity structure will require novel electricity grid structures and new strategies for their operation, control and management to ensure efficiency, security, sustainability, reliability and high quality power supplies. The future grid has to be sufficiently intelligent and flexible to operate reliably with intermittent generation technologies such as wind power, solar and with generation embedded in the distribution grids. A coordinated approach, to overcome both technical and non-technical problems is needed.

\section{REFERENCES}

[1] Distributed Generation in Liberalized Electricity Markets, International Energy Agency, 2002.

[2] Loi Lei Lai (Editor), "Power System Restructuring and Deregulation: Trading, Performance and Information Technology", John Wiley \& Sons, UK, Sept 2001, page 45.

[3] J. E. Kim and J. S. Hwang: "Islanding detection method of distributed generation units connected to power distribution system", PowerCon 2000. International Conference on Power System Technology. Proceedings. IEEE, Perth, WA, Australia, 2000.

[4] S. K. Salman, D. J. King, and G. Weller: "New loss of mains detection algorithm for embedded generation using rate of change of voltage and changes in power factors", Seventh International Conference on Developments in Power System Protection. IEE, Amsterdam, Netherlands, 2001.
[5] H. H. Zeineldin, E. F. El-Saadany, and M. M. A. Salama: "Islanding detection of inverter-based distributed generation", IEE Proceedings-Generation, Transmission and Distribution, vol. 153, pp. 644-52, 2006.

[6] V. John, Z. Ye, and A. Kolwalkar: "Investigation of antiislanding protection of power converter based distributed generators using frequency domain analysis", IEEE Transactions on Power Electronics, vol. 19, pp. 1177-83, 2004.

[7] J. C. M. Vieira, W. Freitas, W. Xu, and A. Morelato: "Performance of frequency relays for distributed generation protection", IEEE Transactions on Power Delivery, vol. 21, pp. 1120-7, 2006.

[8] W. Freitas, W. Xu, C. M. Affonso, and Z. Huang: "Comparative analysis between ROCOF and vector surge relays for distributed generation applications", IEEE Transactions on Power Delivery, vol. 20, pp. 1315-24, 2005.

[9] Z. Ye, A. Kolwalkar, Y. Zhang, P. Du, and R. Walling: "Evaluation of anti-islanding schemes based on nondetection zone concept", IEEE Transactions on Power Electronics, vol. 19, pp. 1171-6, 2004.

[10] H.H. Zeineldin, K. Bhattacharya, E.F. El-Saadany and M.M.A. Salama, "Impact of intentional islanding of distributed generation on electricity market prices", IEE Proceedings - Generation, Transmission and Distribution - March 2006 -- Volume 153, Issue 2, p. 147-154

[11] Kamphuis, I.G.; Hommelberg, M.P.F.; Warmer, C.J.; Kok, J.K., "Massive coordination of dispersed generation using PowerMatcher based software agents", Presented at 19th International Conference on Electricity Distribution, Vienna, Austria, 21-24 May, 2007

[12] Khalil EI-Arroudi,Geza Joos.Intelligent-Based Approach to Islanding Detection in Distributed Generation, IEEE Transactions on power delivery,2007,22(2)

[13] Khalil EI-Arroudi,Geza Joos.Intelligent-Based Approach to Islanding Detection in Distributed Generation, IEEE Transactions on power delivery,2007,22(2)

[14] IEEE Standard for Interconnecting Distributed Resources with Electric Power Systems, IEEE, 2003.

[15] W. El-Khattam and T.S. Sidhu, "Restoration of directional cvercurrent relay coordination in distributed generation systems utilizing fault current limiter", IEEE Transactions on Power Delivery, vol. 23, no. 2, pp. $576-$ 585, April 2008.

[16] P. N. Vovos, A.E. Kiprakis, A.R. Wallace, and G.P. Harrison, "Centralized and Distributed Voltage Control: Impact on Distributed Generation Penetration", IEEE Transactions on Power Systems, vol. 22, no. 1, pp. $476-$ 483, February 2007.

[17] L. L. Lai et al., The Impact of Renewable Energy Sources and Distributed Generation on Substation Protection and Automation, Working Group B5.34 (Convenor: J. A. Gonzalez), CIGRE, Technical Brochure Number 421, August 2010. 